\title{
More than training
}

\author{
Highly engineered materials can play a pivotal role both in boosting the performance of athletes and in \\ stimulating the innate repair of tissue damaged by sports injuries.
}

The face of sports has changed dramatically since the days of the first Olympic Games in ancient Greece. The earliest competitions were held on sand and encompassed little more than foot races. The 2012 Olympics in London, in contrast, will be a display of elite performances across many different sports, which is to a large extent made possible by progress in materials science and technology.

Since the first modern Olympics in 1896, performance in sports as diverse as the $100 \mathrm{~m}$ sprint, pole vault and cycling has increased significantly, by $24-221 \%$ depending on the type of sport ${ }^{1}$. This progress is due to a multitude of factors, especially improved training methods and the early identification of promising talent. In addition to constant performance monitoring and personalized training plans, however, athletes have also benefited from highly improved materials. In fact, some of the largest increases in performance have been seen in sports that rely heavily on equipment.

Olympic one-hour cycling, for example, has seen a performance increase of $221 \%$ over 111 years $^{1}$, which is largely a result of the replacement of heavy metal frames by light carbon fibre composites (Fig. 1). At more modest levels, many other sports such as javelin, skiing and tennis have also benefited from highly engineered materials. In a Commentary in this Focus issue, Mike Caine, Kim Blair and Mike Vasquez review this evolution of sports technology ${ }^{2}$. They illustrate how the design of poles for vaulting moved from wood to aluminium and then on to glass fibre composites, and how each of these changes led to new records. Likewise, improved soft materials such as synthetic fabrics now provide athletes with superior heat management and, in the case of swimsuits, viable reductions in friction.

In view of such progress, critics have coined the term technology doping. For swimming, the emergence of full-body coverage and laminate-based suits led to the tumbling of numerous world records ${ }^{3}$. As many as $94 \%$ of the swimming races at the 2008 Olympics in Beijing were won by athletes wearing swimwear manufacturer Speedo's LZR Racer suit, which included polyurethane structures for body compression. In the course of the following year and after further storming success, the international swimming association eventually tightened equipment
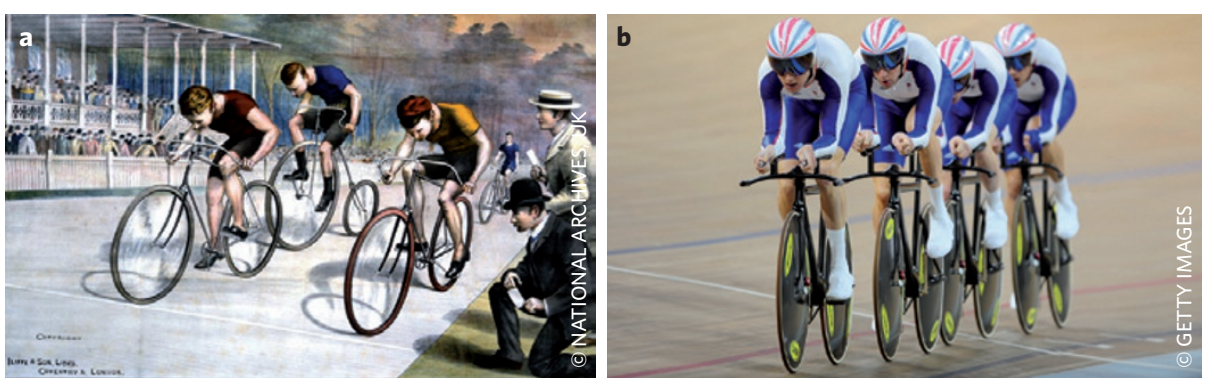

Figure 1 | Engineered materials such as carbon fibre composites have increased the performance of athletes in track cycling. a, Cycle race in 1893. b, Cyclists at the 2008 Beijing Olympic Games.

regulations, effectively excluding laminates from the group of allowed materials.

In an Interview with Tom Waller, the head of Speedo's research and development facility Aqualab, we discuss how the company has adapted to this new playing field ${ }^{4}$. Instead of laminates, they now focus on complex textiles and an integrated design that leverages the fluid dynamics around the entire set of equipment worn by the athlete. Likewise, the banning of zippers and fasteners means that getting dressed for competitive swimming requires considerable preparation, and that female swimmers now need to get into their suit through the arm hole.

It is this dynamic interplay between regulatory bodies and resourceful researchers that makes sports technology an innovation hotbed. Regardless of the pros and cons, elite athletes crucially rely on technological progress to compete. For example, highperformance wheelchairs for competitors in the Paralympics contain lightweight metal alloys and need to be designed with an eye on aerodynamics. Also, when sports injuries occur, all athletes can benefit from advances in tissue engineering and regenerative medicine to stimulate the innate repair of bone and cartilaginous tissue, such as that of the meniscus of the knee joint. In a Commentary reviewing progress in biomaterials for tissue repair, Paul Ducheyne, Robert Mauch and Douglas Smith discuss developments in implantable polymeric and ceramic scaffolds for the delivery of growth factors and cells that support and stimulate the rapid repair of damaged bone and cartilage lesions ${ }^{5}$. They also discuss preclinical strategies for the repair of traumatic spinal cord injuries, which unfortunately can arise from accidents in the practice of sports such as horseback riding, football or diving.

With improvements in orthopaedics, the line between the Olympics and Paralympics may become increasingly blurry. This trend has become most evident in the case of the South African runner Oscar Pistorius, who has been fighting to compete in the Olympics despite his two lower-leg prostheses. The International Association of Athletics Federations (IAAF) had initially banned him from participating in standard competitions in view of possible advantages from his light and flexible carbon fibre limbs. However, after numerous biomechanical and physiological studies, the Court of Arbitration for Sport eventually overruled the IAAF's decision and paved Pistorius's way to the Olympics.

No matter how far sports technology progresses, physiological predisposition ${ }^{6}$ and biomechanics ${ }^{7}$ already distinguish elite athletes from the average individual who is merely in good shape. Further improvements with the help of high-performance materials and developments in sporting equipment should be welcomed as long as they are accessible to every competitor and accepted by the key stakeholders in sports. After all, the goal of technology should be to enable every sportsperson to get the best out of their talent.

\footnotetext{
References

1. Haake, S. J. J. Sports Sci. 27, 1421-1431 (2009)

2. Caine, M., Blair, K. \& Vasquez, M. Nature Mater. 11, 655-658 (2012).

3. Foster, L., James, D. \& Haake, S. Procedia Eng. 34, 712-717 (2012).

4. Nature Mater. 11, 659-660 (2012).

5. Ducheyne, P., Mauch, R. L. \& Smith, D. H. Nature Mater.

11, 652-654 (2012)

6. Abbott, A. Nature 430, 603 (2004).

7. Watts, A. S., Coleman, I., Nevill, A. J. Sports. Sci.

http://doi.org/cq38z6 (2012).
} 